\title{
DEBATE
}

\section{Tobacco, taxation, and fairness}

\section{H V McLachlan}

J Med Ethics 2002;28:381-383

The author defends himself against an attack by Smith and Bopp on his views on smoking and taxation. The theory that, on the grounds of equity and/or fairness, smokers should pay via taxation on tobacco for the health care costs of treating smoking-related medical conditions is discussed and shown to be defective. It is argued that the fundamental mistake that Smith and Bopp make is to confuse and conflate the separate issues of whether particular taxes are fair and whether they are justifiable. The conclusion is reached that an excise duty on tobacco is a good tax. It is a non-fair or even an unfair tax but it is justified on grounds other than fairness.

Correspondence to: Dr H V McLachlan, Reader, Division of Sociology and Social Policy, School of Social Sciences, Glasgow Caledonian University, Cowcaddens Road Glasgow G4 OBA, Scotland;

h.mclachlan@gcal.ac.uk

Accepted 15 April 2002
S mith and Bopp attack what they consider to be my views on taxation and smoking as expressed in a previous article in this journal. I shall restate and defend my position. Some problems with Smith's and Bopp's defence of taxation on tobacco as: “... a means of covering the added health care expenses caused by smokers' exercise of choice" will then be suggested. ${ }^{1}$ In addition, I want to move the debate about the taxation of tobacco forward by questioning the meaning and significance of fairness in this context. Smith and Bopp might well give their readers the impression that I am against the heavy taxation of tobacco. I am not. Often with public policy, what matters is why what is done is done and not merely what is done.

\section{SMOKERS, VIRGINS, EQUITY, AND HEALTH CARE COSTS}

First of all, let us consider my original position. What is at issue centrally is a philosophical principle of taxation presented by Le Grand: the taxation of tobacco in particular was discussed in my article as being illustrative of the principle concerned. ${ }^{2}$ It is Le Grand's contention that, on the grounds of equity, the group of people who voluntarily indulge in what are known to be risky activities (and this group exclusively) should pay through hypothecated taxation for the costs of the health care which that activity causes the need for. ${ }^{3}$

I argued against this. The principle is, I suggested, inherently not particularly equitable. Furthermore, it is not a principle which could, partly for reasons of political practicality, be consistently and equitably applied. The principle that people-individually or collectively-should pay the costs that their voluntary actions occasion might be an appropriate one to apply in some contexts and some types of social organisations, particularly where membership and participation are optional and voluntary. However, in societies, especially in a society such as Britain where health care is provided by the National Health Service (NHS) and funded by taxation, it is not an equitable one-nor on other obvious grounds a suitable one-to apply in relation to health care.

In Britain, would it be equitable were nonvirgins and non-virgins alone required to pay for all the costs of the treatment of sexually related illnesses and conditions such as, for instance, venereal disease and pregnancy? No, I do not think that it would be particularly equitable. Non-virgins should not be required to pay more than virgins in taxation in order to cover the health care costs which they, through their voluntary actions, cause. Similarly, I do not think that it would be particularly equitable to require smokers to foot exclusively the bill for smokingrelated health care costs. Furthermore it would be inequitable were smokers and smokers alone required to pay for the treatment of smokingrelated illnesses while they were also forced, whether or not they were, say, joggers, motorists, drinkers, or virgins, to pay via taxation for jogging, motoring, drinking, and sex-related health care.

Smith and Bopp are right when they say: "Hugh V McLachlan has argued that it is unfair to tax smokers, and smokers alone for the healthrelated costs associated with smoking". 'I did not argue, however, against the taxation, even the very high taxation of tobacco: I argued against a particular principle for justifying it.

Smith and Bopp say: "Taxing smokers is sound public policy" and they also say that this taxation is justified as "... a means of covering the added health care expenses caused by smokers' exercise of choice". ${ }^{1}$ Taxing the purchase of tobaccostrictly speaking, there is no tax on smoking nor on smokers-is, I agree, sound public policy. It does not, however, require the defence which Smith and Bopp try to give it. There are taxes on, for instance, the purchase of television sets, socks, chocolates, perfume, and beer. The justification for these taxes-and this is typical of taxation in general: why should the taxation of tobacco be different?-is not and need not be that it covers the costs of the health care which is necessitated as a consequence of the effects of, respectively, watching television, wearing socks, eating chocolate, wearing perfume, and drinking beer. To say that there is a justification for a tax on the purchase of commodity $\mathrm{X}$ is not the same thing as saying that all health care costs pertaining to illnesses stemming from the consumption of $\mathrm{X}$ should be paid for solely by the consumers of X. 


\section{SMITH AND BOPP ON LE GRAND AND MCLACHLAN}

Smith and Bopp write: "Both McLachlan and Le Grand presume that smoking is a private vice, based upon informed choice, and that the full costs of smoking are visited upon smokers (and smokers alone)". ${ }^{1}$ What an astonishing claim! I presumed in the article no such things (and nor, in his book, does Le Grand). I do not think that the direct and indirect consequences of smoking affect only smokers any more than that the consequences of the actions of non-virgins are visited upon non-virgins alone.

Smith and Bopp say: "Unfortunately, McLachlan's position is based upon a misrepresentation of Le Grand". ${ }^{1}$ I do not fully specify Le Grand's position but I do so fully enough for the argument that I make. I give a fair and true account of as much of Le Grand's theory of equity and taxation as is required to be given for a consideration of his argument. Readers can check and decide for themselves whether Bopp and Smith are correct on this point or I am.

Smith and Bopp say: "McLachlan's final criticism amounts to a simple argument from slippery slope-adopting an excise tax on smoking would result in a plethora of special taxes". ${ }^{1}$ Slippery slopes have nothing to do with my case. I do not argue that a tax on tobacco will lead to other taxes. I talk of smokers, virgins, non-smokers, and non-virgins but I do not expect nor suggest that there will be a tax introduced on sexual intercourse.

\section{THE HYPOTHECATED TAXATION OF TOBACCO}

Smith and Bopp do not fully specify how they think that a hypothecated tax on tobacco should operate (and nor, to my knowledge, does Le Grand). Should taxation on the current purchase of tobacco pay for: A) the costs of current smokingrelated health care or B) the future smoking-related health care costs of current smokers? There are severe-perhaps insurmountable - problems either way.

For instance, if you choose B) then you have the problem of guessing-you cannot know-what the future health care costs will amount to in order to set a rate of taxation which will cover and will do no more than only cover that amount. What, for instance, will the absolute and relative pay of nurses be in the future? What, if any, relevant and presently unknown medical treatments and techniques will become available in the future? How much will they cost?

If you choose A) then among the problems raised is this one. It might turn out that in the future, fewer and fewer people will smoke and that it will not be possible to raise from the future taxation of tobacco enough money to pay for the treatment of those people who currently smoke and will become ill in the future.

Whether you choose A or B, if the rate of taxation of tobacco in the UK is significantly higher than the rate of taxation of tobacco in other countries then some or many people in the UK will evade the UK tax through the buying of smuggled cigarettes.

\section{THE COSTS OF SMOKING}

The question of the precise net costs of smoking and of the net costs of smoking borne by non-smokers is crucial for Bopp's and Smith's argument. They do not give an account, however, of what such costs are and nor do they seem to be aware of the complexity of the problem of calculating them.

There is a possibility, perhaps even a likelihood, that, in Britain, smokers as a group subsidise non-smokers as a group. A strict application of the principle advocated by Smith and Bopp might even require a negative tax on-that is, a subsidisation of - the purchase of tobacco. I would be against that. What would Smith and Bopp say?

It is indicated in a recent research note that the costs to the NHS of deaths through smoking of smokers is estimated to be only $£ 1.7$ billion while the expected tax revenue from tobacco next year is $£ 7.8$ billion. ${ }^{4}$ Furthermore, those who die from smoking would not, were they to have been non-smokers, have been immortal. They would have died from other causes and suffered from other costly illnesses.

Why consider only health care costs? There are various other relevant items of public expenditure: in particular, since smokers, on average, do not live as long as non-smokers, they do not as a group generate the same pension costs as non-smokers as a group.

\section{JUSTICE, FAIRNESS, AND TAXATION}

The crucial mistake which Smith and Bopp make is to conflate and confuse the two following separate questions. Is an excise tax on tobacco a good tax? Is an excise tax on tobacco a fair tax? It is, in my view, not a fair tax but it is a good one. Let me elaborate on "fairness" and on taxation in order to support this paradoxical claim.

I think it is useful to distinguish between "fairness" and "justice". I think that the notion of fairness is an important one but I do not think that it can be analysed. I suspect that it can be defined, if at all, only ostensibly by giving examples of what we think would count as instances of fairness and of unfairness. What counts as fairness too depends, I think, very much on the particular vantage point from we choose to view situations. There is, in my understanding and preferred use of the term, a relationship between justice and rights which does not exist between fairness and rights nor between luck and rights. For instance, I would say that while the deaths of Buddy Holly and John Lennon were both unlucky and unfair, the death of the latter was also unjust. ${ }^{56}$

Buddy Holly died in a plane crash as the result of an accidental error of the pilot, who also died. John Lennon was deliberately murdered. Buddy Holly's death was not an infringement of his rights. We do not have a right not to die. The pilot was not in breach of a duty which he had towards Buddy Holly. We do not have a duty not to make mistakes although we have a duty to try not to make them. John Lennon was denied the enjoyment of a right when he died, the right not to be killed.

With some things, if you cannot do them fairly, then you should not do them at all. With other things, if you cannot do them fairly, then you should do them non-fairly or even unfairly. For instance, if you cannot give someone a fair trial on, say, a murder charge, then you should not give him or her a trial at all. On the other hand, suppose you need, in a dire emergency and for a just war, to raise an army. If you cannot raise the army in a fair way, then you should raise it in a nonfair way or even an unfair way: what matters is that you raise it. Raising taxes is akin to the raising (in some peculiar circumstances) of armies: that they are raised is-but that they are raised fairly is not—crucial.

Taxation, as the means of provision of public finance, is necessary for the survival of the state and of society itself in an advanced industrial context. Furthermore, taxation also funds the provision of goods and services which, even if not essential, are useful. It is in relation to such societal survival and usefulness that taxation is justifiable. It is not clear that the provision of such goods and services or even societal survival itself would be possible on the basis solely of taxation which was fair. No industrial society, I would suggest, has been known to levy only fair taxes. It is not even clear what fair taxation would consist in. Taxes need not be fair in order to be justifiable

I would suggest that a poll tax is the fairest (or least unfair) of taxes. It is also one of the worst. The introduction of the Poll Tax was perhaps Mrs Thatcher's major political error. The problem with the Poll Tax in Britain was not that it was unfair or particularly so but that it was, whether rightly or wrongly, thought to be unfair and, more importantly that it was very difficult and expensive to collect: also, in the incompleteness of it, its 
(partial) collection was unjust and unfair. It was a bad tax, a very bad tax.

Conversely, although it is unfair (or, at least, not fair) heavy taxation on tobacco is thought to be fair: it can be raised without a public outcry. Furthermore, the tax is easy and cheap to collect. The whole point of taxation is to raise money: taxation on tobacco does this bounteously. Excise duty on tobacco is a good tax.

\section{PATERNALISM}

Smith and Bopp say that heavy taxation of tobacco can also be justified on paternalistic grounds. I disagree for two reasons. Paternalism as such is, in general, a poor basis for public policy. Secondly, the taxation of tobacco which is paid by actual smokers-as opposed to the disincentive effect on nonsmokers caused by the existence of tax on tobacco-is not an instance of paternalism. The beneficiaries of the policy are, by definition, not smokers. You benefit from the tax only to the extent that you don't pay it. To penalise individual $X$ for the benefit of $X$ is - whether justified or not-paternalism. To tax individual $\mathrm{Y}$ for the benefit of $\mathrm{X}$ is not-whether justified or not-paternalism: it is, or is more like, authoritarianism.

\section{CONCLUSION}

My position can withstand the criticism of Smith and Bopp. An excise duty on tobacco can be defended but (at least in contemporary Britain) not on the grounds of fairness and/or equity as "... a means of covering the added health care expenses caused by smokers' exercise of choice" despite what Smith and Bopp and Le Grand say. The taxation, indeed, the heavy taxation of tobacco is justifiable but it is justifiable despite its unfairness (or, perhaps, non-fairness) rather than because it is particularly fair or equitable.

\section{REFERENCES}

1 Smith VR, Bopp AE. Smokers and taxes. Journal of Medical Ethics 1999;25:419.

2 McLachlan HV. Smokers, virgins, equity and health care costs. Journal of Medical Ethics 1995;21:209-13.

3 Le Grand J. Equity and choice: an essay in economics and applied philosophy. London: Harper Collins Academic, 1991

4 Davis C. Findings. The Times Higher Education Supplement 2002 Jan 11: 8 .

5 McLachlan HV. Justice, rights and health care: a discussion of the Report of the Commission on Social Justice. International Journal of Sociology and Social Policy 1998;18:65-84.

6 McLachlan HV. Scotland, social justice, health and inequality. In: Nottingham C, ed. The NHS in Scotland: the legacy of the past and the prospect of the future. Aldershot: Ashgate, 2000: 106-23.

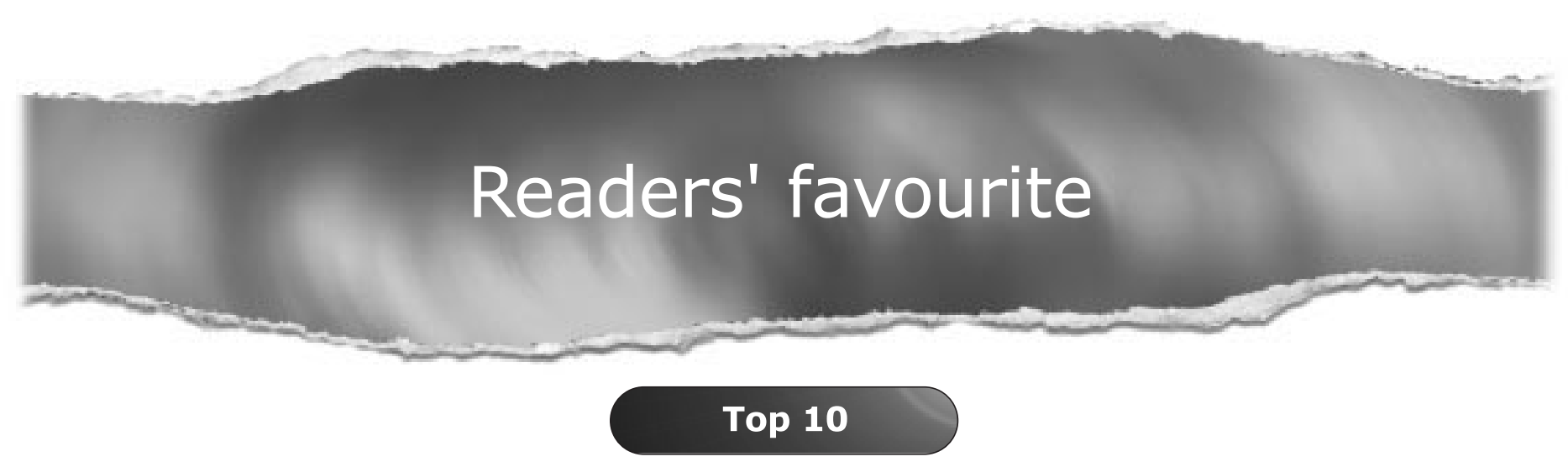

Click on the "Top 10 Papers" button on the homepage to see which are the best read articles each month

www.jmedethics.com 